(Aus dem Universitätsinstitut für pathologische Biologie am Eppendorfer Krankenhause und der Direktorial-Abteilung [Ned. Klinik].)

$\mathrm{X}$.

\title{
Über Beziehungen zwischen Tuberkelbazillen und Schimmelpilzen.
}

\author{
Von
}

\author{
Dr. Hans Schmidt, \\ Assistenten ain Institut.
}

Die Immunitätswissenschaft kennt keine vollkommen abgestimmte Beziehung zwischen Spaltpilzen und Wirtsorganismus, sondern Gruppen- und Verwandtschaftsbeziehungen, die einen um so engeren Kreis in sich begreifen, je feiner die Abstimmung der Probe eingestellt ist. Besonders klar sind diese Beziehungen bei den säurefesten Bazillen durch die Untersuchungen von Much und seinen Mitarbeitern: Hößli, Leschke, Deilmann, Wills, Ċepulič festgestellt worden. Komplementbindungsversuche mit dem Serum Tuberkulöser zeigten, daß die in dem Tuberkelbazillus enthaltenen abgestimmten Stoffe auch in anderen säurefesten Bazillen: Lepra-, Harn-, Thimotheebazillen, Schildkröten-, Blindschleichentuberkelbazillen, wenn auch in geringerer Menge vorhanden sind. Diese Verwandtschaft tritt noch deutlicher hervor, wenn die Probe mit dem Serum. Lepröser angestellt wird. Weitere Forschungen stellten fest, daß gerade die Fettbestandteile die Verwandtschaft der säurefesten Bazillen bedingen. Deycke, und später Deycke und Much hatten in Nastin und später in Tuberkulosenastin hochreaktive Fettkörper dargestellt und gezeigt, daß die säurefesten Stäbchen alle einen Fettkörper enthalten, der dem Nastin und dem Tuberkulonastin sehr nahe verwandt ist, vielleicht mit diesen viele gemeinsame Bestandteile hat. Das Nastin wurde von Deycke aus einer Streptothrixart hergestellt. Die Streptothricheen sind nicht streng säurefest, so daß diese Eigenschaft allein nicht unbedingt für die Verwandtschaft zu den Tuberkelbazillen zu sprechen braucht. Es ist daher von vorneherein nicht ausgeschlossen, daß noch eine Reihe anderer Pilze reaktive Stoffe enthalten können, die denen in den streng säurefesten Stäbchen gleichen, da doch sogar das Chaulmoograöl aus den Samen von Taractogenes KurziiKing, also einer höher stehenden Pflanze mit dem Nastin nahe verwandt zu sein scheint. So lag es nahe auch Schimmelpilze und Hefearten in den Kreis der Betrachtung zu ziehen, um so mehr als die Sporen mancher Hefe und Schimmelarten unter Umständen ziemlich erhebliche Säurefestigkeit aufweisen. 
Von Schimmelpilzen wurde das Penicillium brevicaule gewählt. Die Verarbeitung geschah nach dem Milchsäureaufschließungsverfahren von Deycke und Much.

Einige Wochen alte Kulturen von Penicillium brevicaule. auf schwach saurer Harnbouillon wurden mit Kochsalzlösung zerrieben, gewaschen und getrocknet. Die getrocknete und pulverisierte Masse wurde dann der aufschließenden Wirkung von $1 \%$ Milchsäure in physiologischer NaCl-Lösung mit $0,5 \%$ Phenol für einige Monate ausgesetzt und dann die Lösung durch scharfes Zentrifugieren von dem Rückstand getrennt. Der Rückstand wurde gewaschen, getrocknet und zu feinem Pulver zerrieben. Fin Teil desselben wurde mit $0,5 \%$ Phenol NaClLösung fein emulgiert und stellte Penic. R. dar. Ein Teil der überstehenden Lösung wurde, als Penic. L., mit Soda neutralisiert. Der andere Teil des Rückstandpulvers wurde mit heißem Äther ausgezogen, welcher beim Verdunsten eine fettige, ölige Masse hinterließ, die in Alkohol gelöst und in NaCl-Lösung emulgiert, den Penic.-Fettbestandteil darstellte, während das zurückbleibende mehrmals mit heißem Äther gewaschene Pulver, in NaCl-Lösung emulgiert den Penic. A.-Bestandteil bildete.

Zunächst wurden die L.- und R.-Präparate mit der Quaddelprobe bei akitv Tuberkulösen und bei solchen, die klinisch keine nachweisbare Tuberkulose aufwiesen geprüft. Dabei wurden gleichzeitig Proben mit MTbL. und MTbR., in den Verdünnungen $\mathrm{L} .=1: 10000, R .=1: 1000000$ angestellt. Es zeigte sich jedoch sehr bald, daß die für Penic. L. $=1: 10$ und Penic. R. = $1: 7$ gewählte Verdünnung noch zu groß war, insofern die Quaddelreaktionen kaum erkennbar waren, was jedoch für $\mathrm{TbL}$. und $\mathrm{TbR}$. in den angewandten Verdünnungen für eine Reihe von Fällen ebenfalls zutraf. Es wurden daraufhin stärkere Konzentrationen gewählt: TbL. $=1: 1000$, TbR. $=1: 100000$, Penic. L: $=1: 1$, Penic. R. = $1: 2$. DieseLösungen wurden an den in folgender Tabelle aufgezählten 8 Fällen geprüft:

\begin{tabular}{|c|c|c|c|c|}
\hline MTbL. & Penic. L. & MTbL. & Penic. R. & \\
\hline+ & $\mathbf{0}$ & $+(+)$ & + & Tb.-Drüsenschwellungen \\
\hline+ & $(+)$ & ++ & $+t$ & Rechts Lungentuberkulose \\
\hline$(+)$ & $(+)$ & + & + & Pleuritis, Verdacht auf Spitzentbc. \\
\hline $\mathbf{0}$ & 0 & $(+)$ & $(+)$ & Beiderseitige Lungentbc. \\
\hline $\mathbf{0}$ & 0 & $(+)$ & + & Polyarthritis rheumatica \\
\hline $\mathbf{0}$ & $\mathbf{0}$ & $(+)$ & $(t)$ & Empyem; sekund. Tbe. \\
\hline 0 & 0 & + & $(+)$ & Polyarthritis rheum. \\
\hline+ & $(+)$ & $+t$ & $(+)$ & Malaria tert. chron. \\
\hline
\end{tabular}

Ein Blick auf die Tabelle zeigt, daß im allgemeinen da, wo die Tuberkelbazillen-Partigene eine positive Reaktion gaben, auch die Penicillium-Partigene eine positive Quaddelreaktion gaben. Dieselbe war jedoch fast immer schwächer und, wenn man außerdem berücksichtigt, daß die Penicillium-Partigene fast unverdünnt in Anwendung kamen, so läßt sich vorderhand daraus nur der Schluß ziehen, daß das Penicillium brevicaule gewisse reaktive Stoffe enthält, die denen des Tuberkelbazillus vielleicht gleichen, jedenfalls aber in sehr viel 
geringerer Menge darin enthalten sind, so daß die Verwandtschaft, wenn überhaupt, eine sehr entfernte ist. Eine Prüfung der Fettbestandteile durch die Quaddelprobe und eine solche aller Penicillium-Partigene mit dem Komplementbindungsverfahren stehen noch aus. Es ist daher, nach dem was wir über die Bedeutung der Fette bei den säurefesten Stäbchen wissen, noch nicht möglich ein 'endgültiges Urteil über die verwandtschaftlichen Beziehungen zwischen dem Tuberkelbazillus und diesem Schimmelpilz zu fällen. Bei der Beurteilung der Quaddelprobe muß man sich vergegenwärtigen, daß auch manche saprophytischen Luftkeime wie Sarzinen unter Umständen in der Quaddelprobe eine positive Reaktion zu geben imstande sind, ohne daß man daraufhin auf verwandtschaftliche Beziehungen zu Tuberkelbazillen schließen würde.

Die Ergebnisse weiterer mit den Partigenen von Schimmelpilzen und Hefearten auszuführenden Versuche werden später mitgeteilt werden. Herrn Dr. Weiß, der die Ausführung der Quaddelproben übernommen hatte, möchte ich auch an dieser Stelle meinen verbindlichsten Dank aussprechen.

\section{Nachtrag während des Druckes.}

Nachdem die Quaddelprobe gezeigt hatte, daß die Reaktionen mit Penicillium $\mathrm{L}$. und R. in gewissem Grade gleichsinnig mit denen von MTbL. und MTbR. verlaufen, lag es nahe die Möglichkeit einer solchen Beziehung auch durch das Komplementbindungsverfahren festzustellen.

Da das Alt-Tuberkulin Koch stärkere komplementbindende Eigenschaft hat, wie MTbL. und MTbR., so wurde für die Untersuchung der Sera auf das Vorhandensein abgestimmter Tuberkuloseimmunstoffe mit der Komplementbindung das Alt-Tuberkulin Koch herangezogen, und in seiner Wirkung auf das Serum mit der von Penicillium $L$. und $R$, verglichen.

Die in einem Vorversuche festgestellte halbe unterbindende Menge betrug für Alt-Tuberkulin Koch $0,03 \mathrm{ccm}$; für das $1: 2$ verdünnte und mit $1 / 10 \mathrm{n} . \mathrm{NaOH}$ neutralisierte Penicillium L. $0,3 \mathrm{ccm}$ und für das $1: 10$ verdünnte Penicillium $R$. $0,15 \mathrm{ccm}$.

Es wurden nun 43 beliebige Sera genommen und mit diesen die drei Stoffe in Gegenwart von frischem Meerschweinchenkomplement in der üblichen Weise aufeinander einwirken gelassen.

Von diesen reagierten 28 mit allen Antigenen negativ, 9 gaben nur mit AltTuberkulin Koch eine Hemmung, und zwar war diese Hemmung nur in 3 Fällen vollständig; in den anderen war es zu schwacher Hämolyse gekommen.

Die übrigen Sera zeigen die in folgender Tabelle angeordneten Befunde;

\begin{tabular}{l|c|c|c}
\hline \hline & Alttuberkulin Koch & Penic. L. & Penic. R. \\
\hline 13 & ++ & +++ & +++ \\
14 & ++ & - & +++ \\
18 & + & + & + \\
24 & +++ & +++ & ++ \\
30 & ++ & + & +
\end{tabular}


Eine Beziehung zwischen diesen Hemmungen und dem Ausfall der Wassermannschen Reaktion besteht nicht. Keiner dieser 6 Fälle hatte eine Lungenoder anderweitige Tuberkulose noch eine Pilzerkrankung, die klinisch nachweisbar wären.

So klein die Zahl ist, so geht aus dieser Beobachtung doch hervor, daß überall da, wo eine starke Komplementbindung mit Alt-Tuberkulin Koch auftrat, auch mehr oder weniger deutliche Reaktionen mit den Partialantigenen von Penicillium brevicaule auftraten; ioh stehe nicht an, dasselbe ebenfalls für andere Penicilliumarten möglich $\mathrm{zu}$ halten.

Leider erwies sich eine Komplementbindung mit den Fettlipoiden von Penicillium brevicaule als nicht durchführbar, insofern auch eine sehr große Menge desselben keine selbstbindende Eigenschaft aufwies. Es sind jedoch Versuche im Gange, die zeigen sollen, wie weit gerade die Fettkörper von Tuberkelbazillen mit denen der Penicillium- und Mukorarten in ihrer Reaktion auf den tuberkulösen Organismus übereinstimmen und ob es möglich ist, das Iŕrankheitsbild Tuberkulöser durch dje Einverleibung der Schimmelpilzpartigene zu beeinflussen.

Darüber wird später berichtet werden. 